\title{
An Early Palaeolithic site near Saiwan (Sultanate of Oman)
}

\author{
PAOLO BIAGI
}

Dipartimento di Scienze Storico-Archeologiche e Orientalistiche, University of Venice, Italy

The Author describes a lithic assemblage attributable to the Early Palaeolithic, discovered in the winter of 1984-85 near Saiwan in central-eastern Oman. The chert assemblage, characterized by large-sized artefacts with plain, sloping, striking platform, various types of hand-axes, side scrapers and cores, is probably to be attributed to a late phase of the Acheulian Culture.

The site of Saiwan was accidentally discovered by the Author and other members of the Italian Archaeological Expedition in December 1984 during a field excursion in centraleastern Oman. Its approximate location is some twelve kilometres west-north-west of Saiwan in an area of longitudinal, red, sand dunes, that constitute the south-westernmost appendix of the Wahiba Sands formation, six kilometres to the east of the shores of a dried, quaternary, lake basin (Fig. 1). The site, at present crossed by a track, was easily recognizable thanks to the presence of a great number of weathered chert artefacts lying on its surface. A few hundred of these were collected by five persons in one hour and are now in the stores of the Ministry of National Heritage and Culture of the Sultanate of Oman (1).

\section{The chipped stone assemblage}

The assemblage consists of some three hundred artefacts obtained from a variety of pale yellowish brown chert (10 YR6/2). Many of them have a thick patina of mod- erate yellowish (10 YR5/4) colour (2) and one or both surfaces partly eolised. It comprises 206 unretouched, complete artefacts, that were measured to develop the diagrams and the histograms of Fig. 2 (3). The industry mainly consists of flat $(46.7 \%)$ tools, followed by carinated/flat $(21.8 \%)$ and very flat $(19.0 \%)$ pieces. The macroliths represent $96.6 \%$ of the total assemblage which is composed, in descending order, of blade-like flakes $(29.1 \%)$, blades $(26.2 \%)$, flakes $(25.2 \%)$, narrow blades $(8.7 \%)$, wide flakes $(8.1 \%)$ and very wide flakes $(2.7 \%)$. Many unretouched artefacts have wide, high-angled, plain striking platforms, typical of the hard-hammering "Clactonian" technique; 50\% are corticated. Both the instruments and the cores are described following the typological classification of F. Bordes (4).

\section{Hand-axes}

The instruments include eleven bifacial handaxes mainly chipped from chert nodules or, more rarely, from large flakes, with a flaked, bifacial retouch that gives them a characteristic sinuous profile. Simple, continuous, com- 


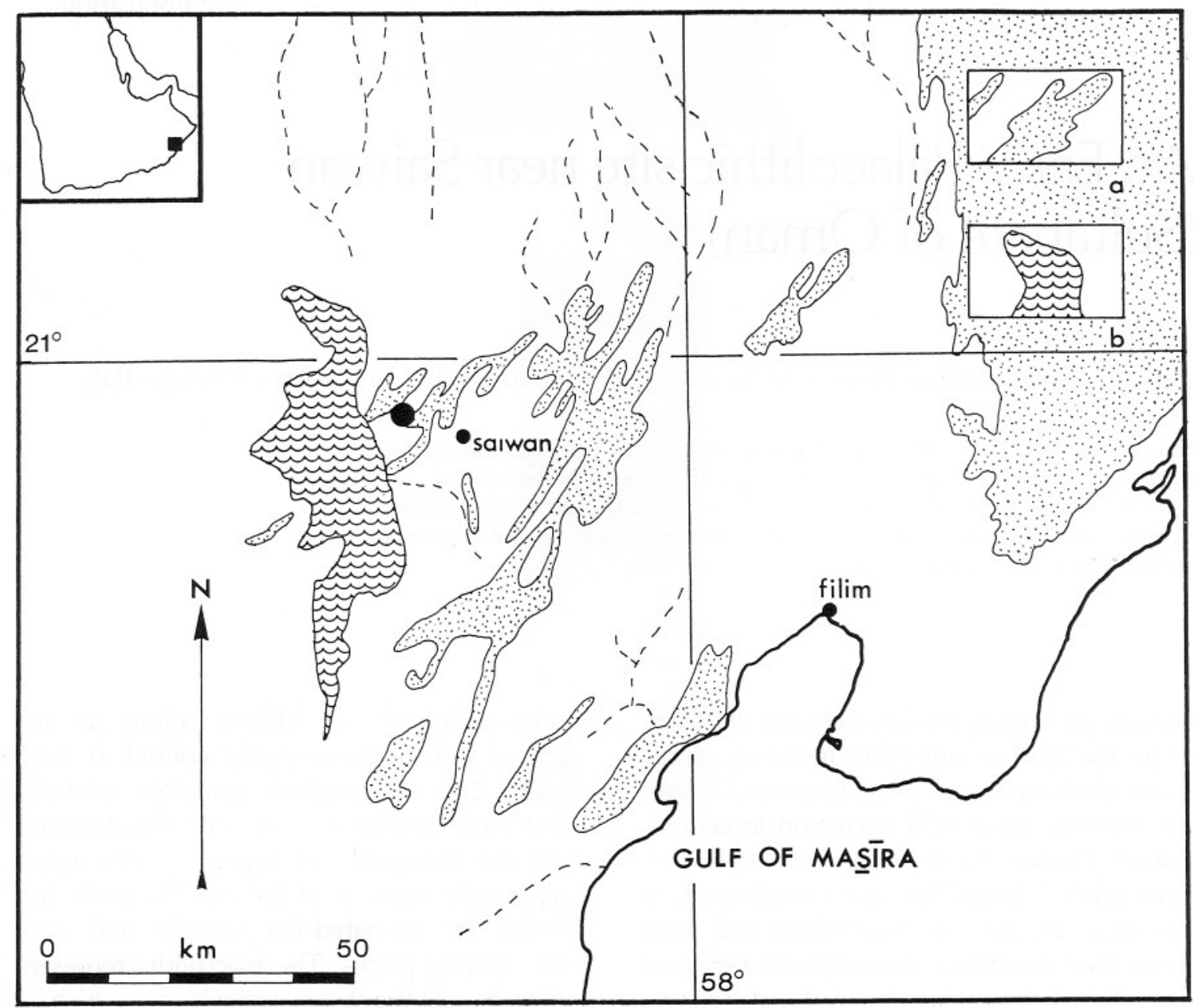

Fig. 1.

Saiwan: approximate location of the Early Palaeolithic site (dot). a) sand dunes, b) dry quaternary lake basin (Drawn by P. Biagi).

plementary, retouch sometimes occurs along one or both edges. Most hand-axes are partly corticated on one or both surfaces. According to their dimensions, they fall within a welldefined spot of band IV of Bordes's diagram (Fig. 3) (5), characterized by ovals-discoidslimandes. More precisely they are to be attributed to the following categories: oval (Fig. 4: 2, 5, 6), discoid (Fig. 4: 3), limande (Fig. 4: 1) and lageniforme (Fig. 5: 4, 5). Only one sub-triangular hand-axe (Fig. 5: 3) falls into band II. Of particular interest is the presence of two bifacial, elongated, lageniforme handaxes with rounded, proximal, and pointed, distal ends.

\section{Bifacial discoids}

These are thick, corticated instruments obtained with centripetal strokes on both surfaces (Fig. 5: 1, 2). A marginal, simple retouch is sometimes present along part of the edge. Some are probably to be interpreted as bifacial flake cores. 

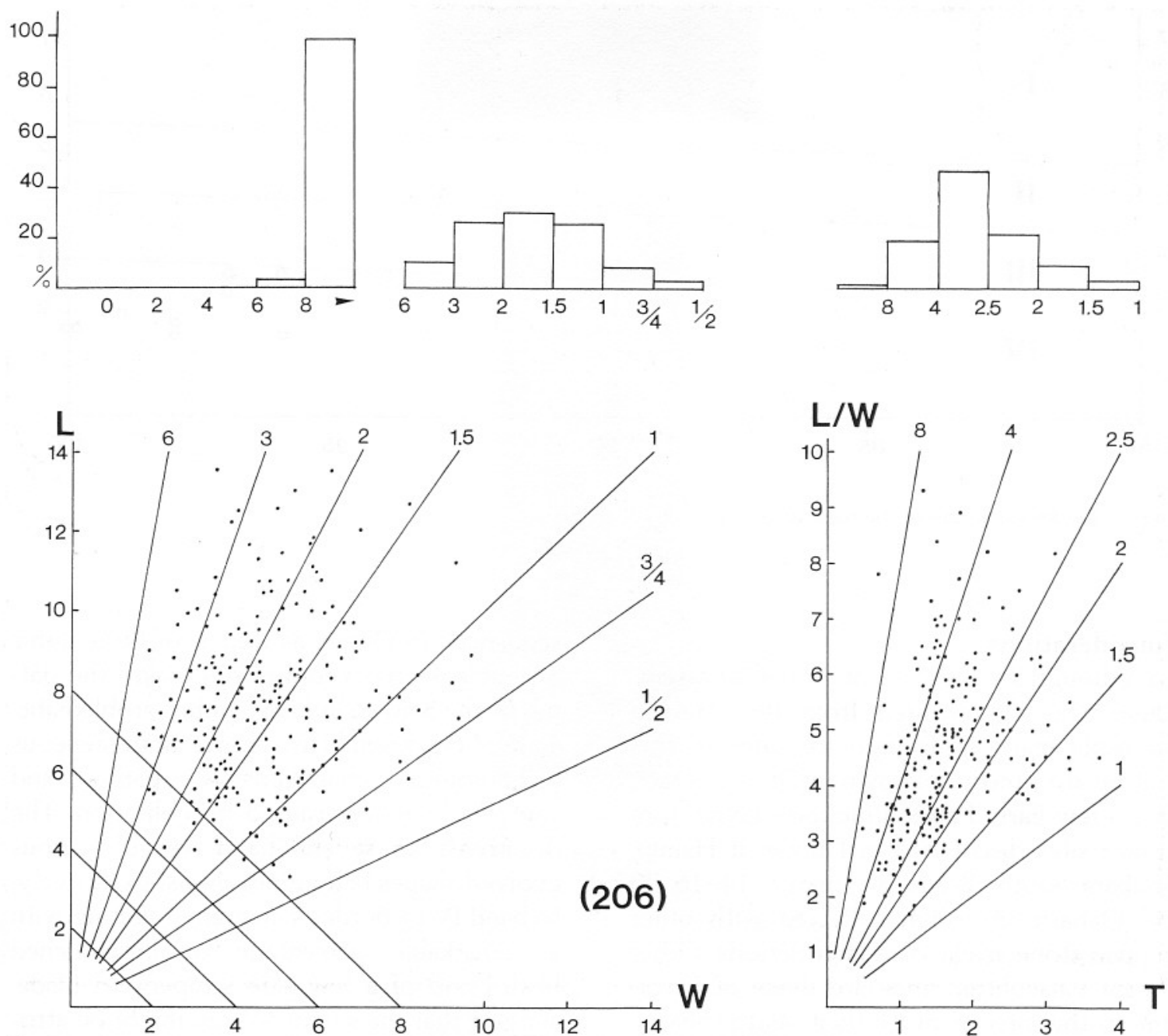

Fig. 2.

Saiwan: length/width and length-width/thickness diagrams and histograms of the complete, unretouched artefacts (Drawn by P. Biagi).

\section{Side scrapers}

This group includes a variety of types, including: one thick bifacial, bitransverse specimen obtained from a wide flake (Fig. 6: 1); one transverse from a large flake, with deep, simple retouch (Fig. 6: 2); some others from flakes with marginal, simple, inverse, lateral (Fig. 6: 3) or with marginal, simple, alternative (Fig. 6: 4) or bilateral (Fig. 6: 5) retouch. Two other instruments are from blades: one has marginal, simple, bilateral retouch (Fig. 6: 6), and the other, marginal, simple, left retouch (Fig. 6: 7).

\section{Cores}

Apart from the discoids, the assemblage includes four blade cores, only one of which has an oblique platform prepared with one single stroke (Fig. 6: 8). The striking platform is plain and oblique in the other cases (Fig. 6: 9-11). 


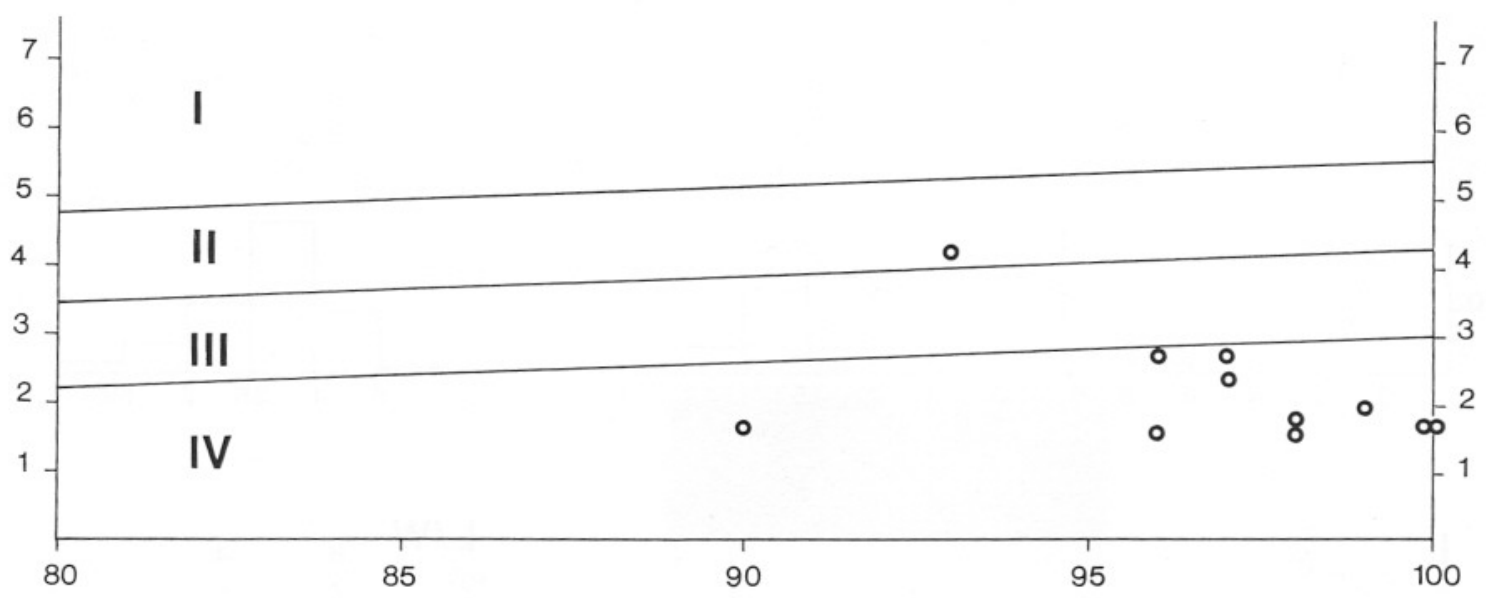

Fig. 3.

Saiwan: Bordes's diagram of the hand-axes (Drawn by P. Biagi).

\section{Considerations}

Even though the presence of Acheulian assemblages was documented from the Arabian Peninsula many years ago (6), sites of this Culture are almost unknown in Oman. In fact, only a few Early Palaeolithic tools come from surface sites discovered in Dhofar at Hanun, Ghubara South, Wady al Umayri 14-16 (7) and Qaharir (8), often collected with other chipped stone artefacts of later periods. Other Omani Palaeolithic finds are those of Sawaqim, in the interior of Quriyat, and probably that of PDO at Muscat (9). Apart from these, no site of this period is recorded from the territory surrounding the Wahiba Sands, accurately investigated in the late Eighties (10). A previous survey in the region nearby, along the western fringe of the sands, was carried out by B. de Cardi and her team. It led to the discovery of many sites of various ages, including many aceramic ones, none of which is attributable to the Palaeolithic (II).

The absence of reliable Middle Pleistocene sequences, in Oman, as well as of Palaeolithic assemblages recovered in situ makes the dating of the Saiwan industry rather problematic. The whole assemblage shows homogeneous technological characteristics, patina and smoothed surfaces caused by eolisation. The occurrence of several hand-axes of various evolved shapes belonging, almost exclusively, to band IV of Bordes's diagram, together with a remarkable percentage of unretouched blades and of a few side scrapers on blade, suggest that the site of Saiwan might be attributed to a late period in the development of the Acheulian Culture.

\section{Acknowledgements}

The Author is very grateful to Dott. Ali Ahmed Bakhit al-Shanfari, Director of Antiquities of the Sultanate of Oman, who provided every sort of facility during his stay in Oman as a Member of the Italian Archaeological Expedition. Special thanks are due to all the participants in the 1984-85 mission who took part in the field excursion during which the site of Saiwan was discovered, as

Fig. 4.

Saiwan: hand-axes: limande (1), oval (2, 5, 6), discoid (3), fragment (4) (1:2) (Drawn by G. Bombonato). 

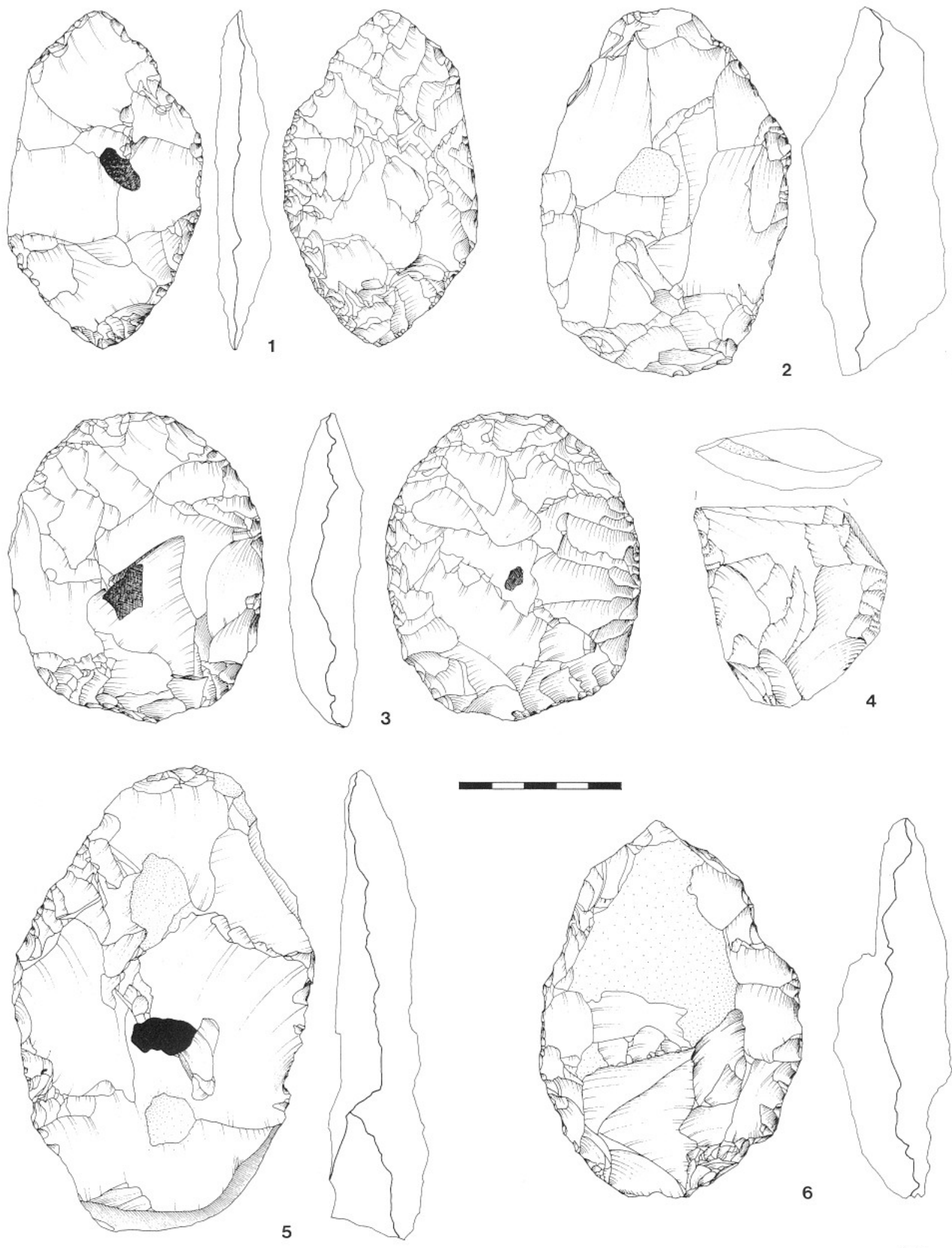

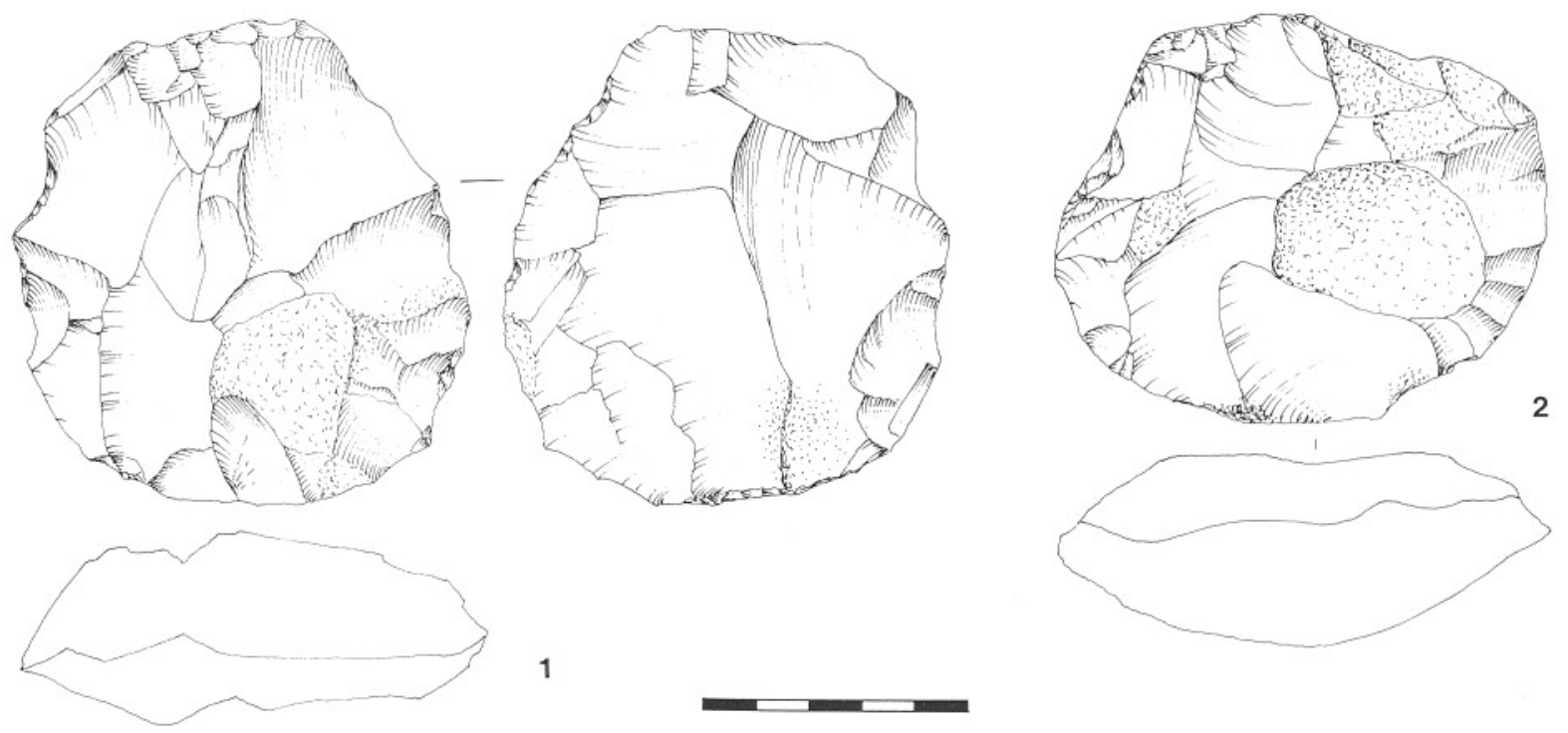

1
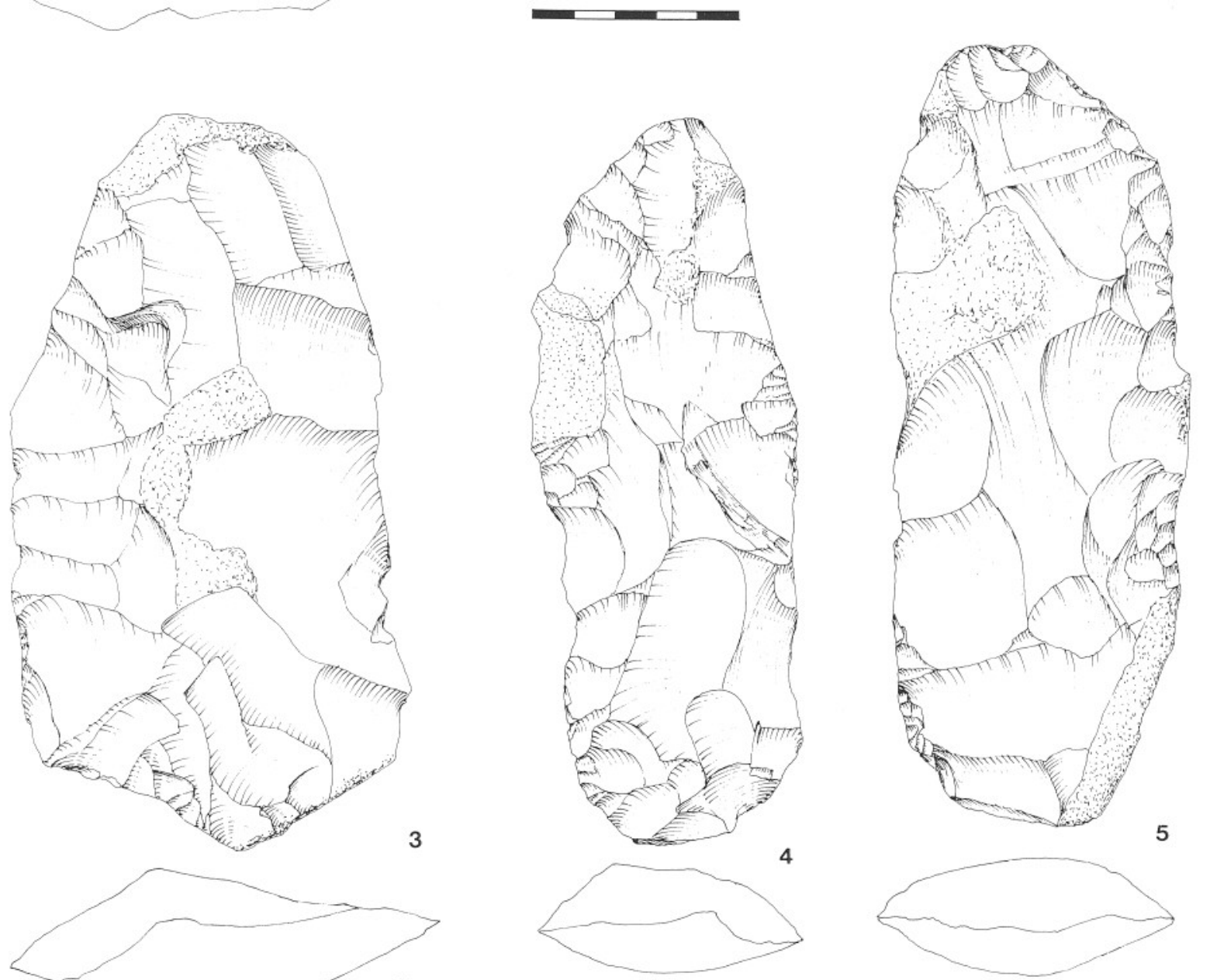

Fig. 5.

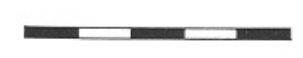

Saiwan: bifacial discoids (1, 2); hand-axes: sub-triangular (3), lageniformes $(4,5)$ (1:2) (Drawn by P. Biagi and G. Almerigogna). 

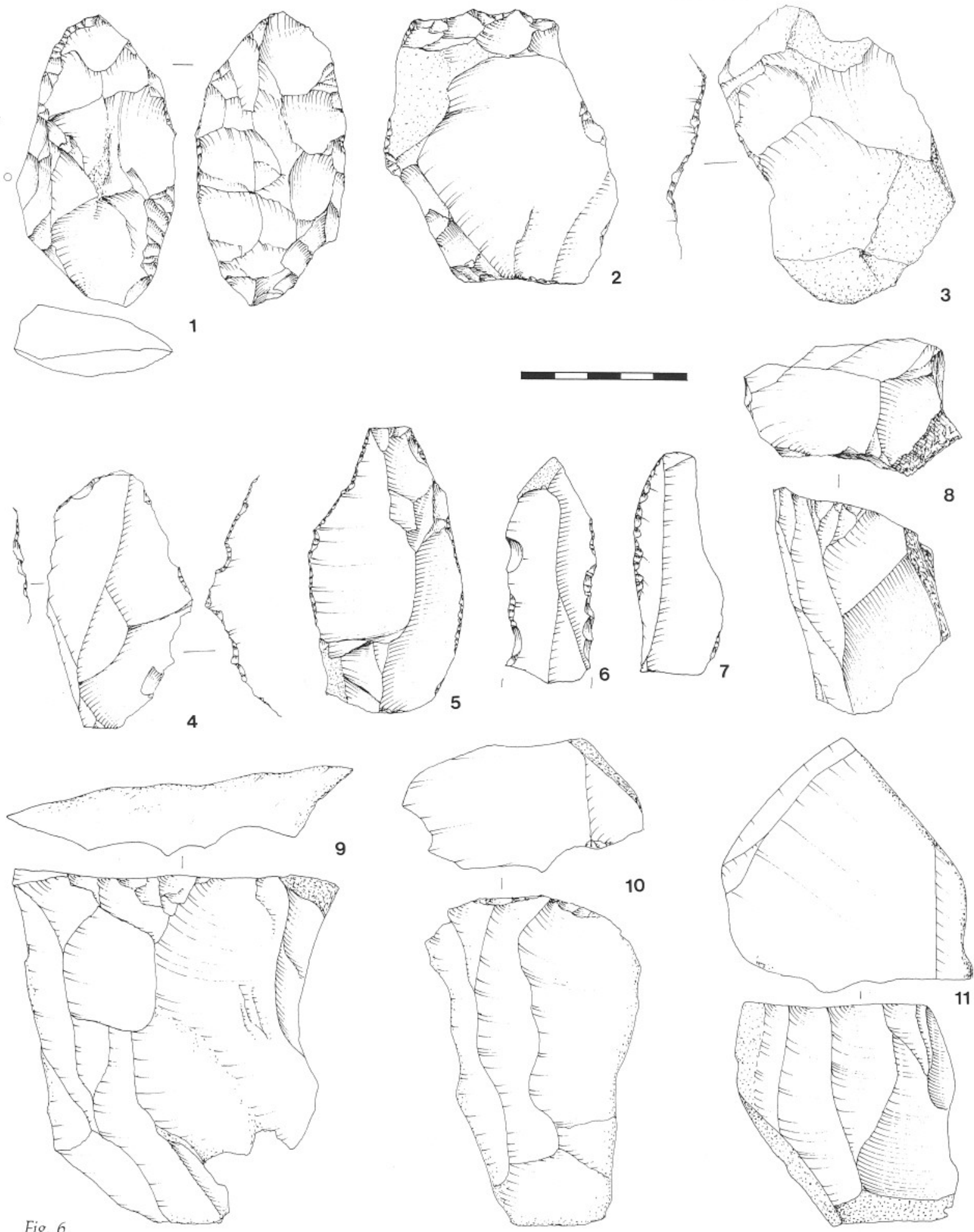

Fig. 6 .
Saiwan: bifacial scraper (1), transverse scraper (2), side scrapers (3-7), blade cores (8-11) (1:2) (Drawn by P. Biagi and G. Almerigogna). 


\section{P. BIAGI}

well as to Dott. A. Pessina who was of great help during the analysis of the artefacts described in this article.

\section{References}

1. The Author is grateful to M. Coltorti, R. Maggi, R. Nisbet and I. Tiscornia who collected most of the artefacts described in this note.

2. Colours of the Munsell Soil Color Charts. Munsell Color Corporation, Baltimore: 1971.

3. The length/width and length-width/thickness diagrams and histograms have been developed following Bagolini's method. Bagolini B. Ricerche sulle dimensioni dei manufatti litici preistorici non ritoccati. Annali dell'Università di Ferrara. Sezione XV. Paleontologia Umana e Paletnologia 1 (10): 1968: 196-219.

4. Bordes F. Typologie du Paléolithique ancien et moyen. Paris, CNRS, 1988.

5. Bordes F. Typologie du Paléolithique: 71-76, translated according to Gamble C. The Palaeolithic settlement of Europe. Cambridge: University Press; 1986: 396-397.

6. Caton-Thompson G. Some palaeoliths from South Arabia. PPS 19: 1953: 189-218; Field H. Ancient and modern man in Southwestern Asia: II. Coral Gables: University of Miami Press, 1961: 26-63; Kapel H. Atlas of Stone Age Cultures of Qatar. Aarhus: Aarhus
University Press, 1967; Smith G. H. The stone industries of Qatar. In De Cardi B, ed. Qatar archaeological report. Excavation 1973. Oxford: Oxford University Press, 1978: 35-38.

7. Villiers-Petocz L E. Some notes on the Lithic collections of the Oman Department of Antiquities. JOS 10: 1989: 51-59.

8. Pullar J \& Jäckli B. Some aceramic sites in Oman. JOS 4: 1978: 53-74.

9. Uerpmann H-P. pers. comm. 1986.

10. Edens C. Archaeology of the sands and adjacent portions of the Sharqiyah. In: Scientific results of the Royal Geographic Society's Oman Wahiba Sands Project 1985-1987. JOS Special Report 3: 1988: 113-130.

11. Doe B. Gazetteer of sites in Oman, 1976. JOS 3: 1977: 35-58; Smith G. New Neolithic sites in Oman. JOS 2: 1976: 189-198; Smith G. New prehistoric sites in Oman. JOS 3: 1977: 71-81.

Address:

Paolo Biagi

Dipartimento di Scienze Storico-Archeologiche e Orientalistiche

Università di Venezia

Palazzo Bernardo. S. Polo 1977A

I-30125 Venice

Italy 

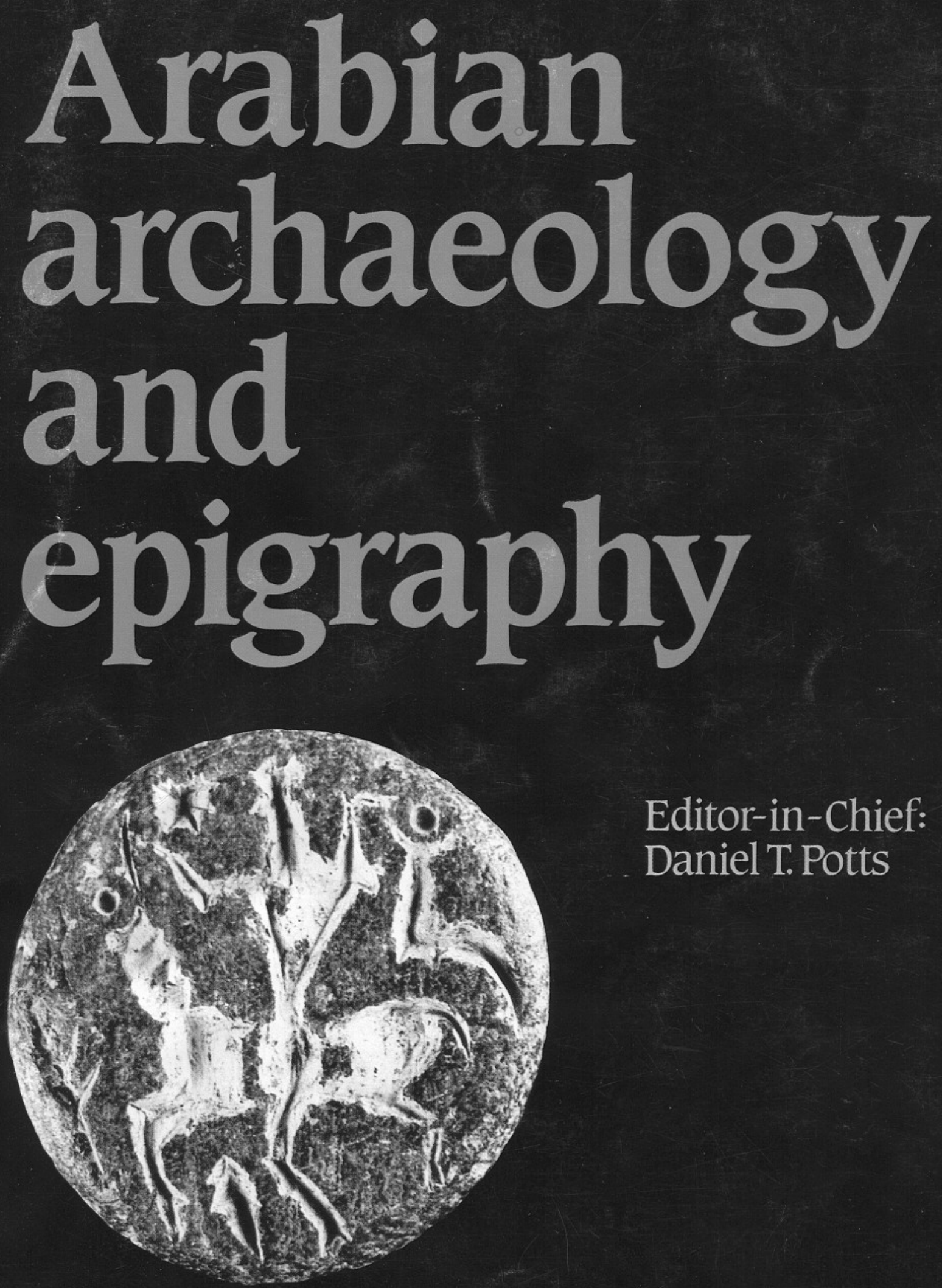

Editor-in-Chief: Daniel T. Potts 